\title{
Lymphocyte Transformation in Patients with Acute Lymphoblastic Leukaemia
}

\author{
LINDSAY H. JONES， R. M. HARDISTY， D. G. WELLS， H. E. M. KAY
}

British Medical fournal, 1971, 4, 329-330

\section{Summary}

The response of lymphocytes to phytohaemagglutinin was tested as an index of lymphocyte function in patients with acute lymphoblastic leukaemia in remission. No significant differences were found in the results of tests on lymphocytes from patients treated with B.C.G. and those from patients given methotrexate, nor was any difference detected between patients and controls.

\section{Introduction}

There is some evidence that immune reactions, either natural or artificially enhanced, may play a part in the response to treatment of acute lymphoblastic leukaemia (Mathé, 1969). If so, it is probable that lymphocytes are involved, and it becomes important to know, firstly, whether there is any defect in lymphocyte function in acute lymphoblastic leukaemia; secondly, the effect, if any, of treatment, including immunotherapy; and, thirdly, if the length of remission is related to lymphocyte reactivity. In recent years many different functions and products of lymphocytes have been described, but satisfactory standardized tests are few; one which has been most widely used is the response of blood lymphocytes to phytohaemagglutinin. By any technique this test gives quite a wide range of normal variation, both from one individual to another and from time to time in the same individual, but in some congenital and acquired immunity deficiency states a lack of responsiveness can be clearly shown (Lischner et al., 1967; Levene, 1970; Marshall et al., 1970). We have used this test as an index of lymphocyte function in patients with acute lymphoblastic leukaemia in remission on various forms of therapy.

\section{Patients}

Forty patients with acute lymphoblastic leukaemia were studied. Twenty-two patients had been entered in an immunotherapy trial conducted by the M.R.C. Leukaemia Committee, designed to compare the efficacy of B.C.G. and methotrexate for maintenance of remissions. It is described in more detail in a preliminary progress report (Medical Research Council, 1971). These patients had all received a five-month course of chemotherapy, including prednisolone, vincristine, mercaptopurine, methotrexate, and L-asparaginase; 12 were subsequently maintained on weekly BCG and six on methotrexate, while five received no further therapy until relapse. Eight of these patients were being treated at the Hospital for Sick Children, 10 at the Birmingham Children's Hospital,

\footnotetext{
Institute of Child Health and Hospital for Sick Children, Great Ormond Street, London WC1N 1EH LINDSAY H. JONES, M.A., Research Fellow

R. M. HARDISTY, M.D., F.R.C.P., Professor of Haematology

Department of Clinical Pathology, Royal Marsden Hospital, London SW3 6JJ

D. G. WELLS, M.B., B.S., Senior Registrar

H. E. M. KAY, M.D., F.R.C.P., Consultant Pathologist
}

and four at the Royal Marsden Hospital. The remaining 18 patients (all from the Royal Marsden Hospital) had received similar chemotherapy but without L-asparaginaseeight were receiving weekly B.C.G. when tested and 10 were on no therapy. Blood samples were taken seven days after the preceding dose of B.C.G., or three days after the preceding dose of methotrexate. Ninety-five tests were performed at the Institute of Child Health on the 18 patients from the Hospital for Sick Children and the Birmingham Children's Hospital ( 1 to 12 tests per patient), and 35 tests at the Royal Marsden Hospital on their 22 patients (one to five tests per patient).

\section{Methods}

Lymphocytes were separated by simple settling of red cells from heparinized blood; in a few cases carbonyl iron and methyl cellulose were used to remove polymorphs (Coulson and Chalmers, 1967). Transformation by phytohaemagglutinin was tested at the Institute of Child Health by a modification of the method of Marshall et al. (1970) and at the Royal Marsden Hospital by a modification of the method of Pentycross (1968). In all cases the cells were cultured for 72 hours with and without phytohaemagglutinin, and the degree of transformation assayed by the uptake of tritiated thymidine into trichloroacetic-acid-precipitable material, as measured by liquid scintillation counting. Control cultures of lymphocytes from one or two healthy adults were run in parallel with each of the test cultures.

Each patient's response was expressed as a percentage of the corresponding mean control response, after subtraction of the unstimulated from the stimulated count in each case. Since the distribution of these percentages was approximately log normal, log transformations were used for statistical analysis.

\section{Results}

Using the mean log response of each patient no significant difference was found between the results obtained in each laboratory, either for all treatment groups together or for B.C.G. and no-treatment groups separately. Because appreciably more tests per patient were carried out at the Institute of Child Health than at the Royal Marsden Hospital,

Mean Phytohaemagglutinin Response of Leukaemic Patients According to Treatment

\begin{tabular}{|c|c|c|c|c|c|c|}
\hline \multicolumn{3}{|c|}{ Treatment } & $\begin{array}{c}\text { No. of } \\
\text { Patients }\end{array}$ & $\begin{array}{l}\text { Mean PHA } \\
\text { Response* }\end{array}$ & $t$ & $\mathbf{P}$ \\
\hline $\begin{array}{l}\text { B.C.G. } \\
\text { No therapy }\end{array}$ & $\because$. & $\begin{array}{l}. . \\
\cdots\end{array}$ & $\begin{array}{l}19 \\
15\end{array}$ & $\begin{array}{l}1.9468 \\
1.9042\end{array}$ & \} 0.0752 & $>0.25$ N.S. \\
\hline $\begin{array}{l}\text { B.C.G. } \\
\text { Methotrexate }\end{array}$ & $\begin{array}{l}\cdots \\
\cdots\end{array}$ & $\begin{array}{l}\cdots \\
\cdots\end{array}$ & $\begin{array}{r}19 \\
6\end{array}$ & $\begin{array}{l}1.9468 \\
2.0742\end{array}$ & \}-0.7162 & $>0.25$ N.S. \\
\hline $\begin{array}{l}\text { No therapy } \\
\text { Methotrexate }\end{array}$ & $\because$. & $\begin{array}{l}. \\
\cdots\end{array}$ & $\begin{array}{r}15 \\
6 \\
\end{array}$ & $\begin{array}{l}1.9042 \\
2.0742\end{array}$ & \}-1.462 & $>0.1$ N.S. \\
\hline $\begin{array}{l}\text { All patients } \\
\text { Controls }\end{array}$ & $\because$. & $\because$. & $\begin{array}{l}40 \\
40\end{array}$ & $\begin{array}{l}1.9499 \\
2.0000\end{array}$ & \}$-1 \cdot 1258$ & $>0.25$ N.S. \\
\hline
\end{tabular}

* PHA response $=\log \left(\frac{\text { Patient's (PHA-unstimulated) c.p.s. }}{\text { Control's (PHA-unstimulated) c.p.s. }} \times 100\right)$ 
a similar comparison between the results of the two laboratories was made using one test selected at random from each patient; again the results did not differ significantly. It was therefore felt justifiable to pool the results from the two laboratories.

In the Table the mean results for each treatment group are compared; it can be seen that there is no significant difference between any of the groups, nor between the mean results of all patients together and the controls.

From Fig. 1 it seems that the mean phytohaemagglutinin response for each patient is unrelated to the total duration of remission, from the end of intensive chemotherapy to the next relapse. In Fig. 2 the results of individual tests on the 31 patients who have so far relapsed are shown in relation to the time from testing to the next relapse; there is no evidence of any systematic change in lymphocyte responsiveness throughout the course of a remission.

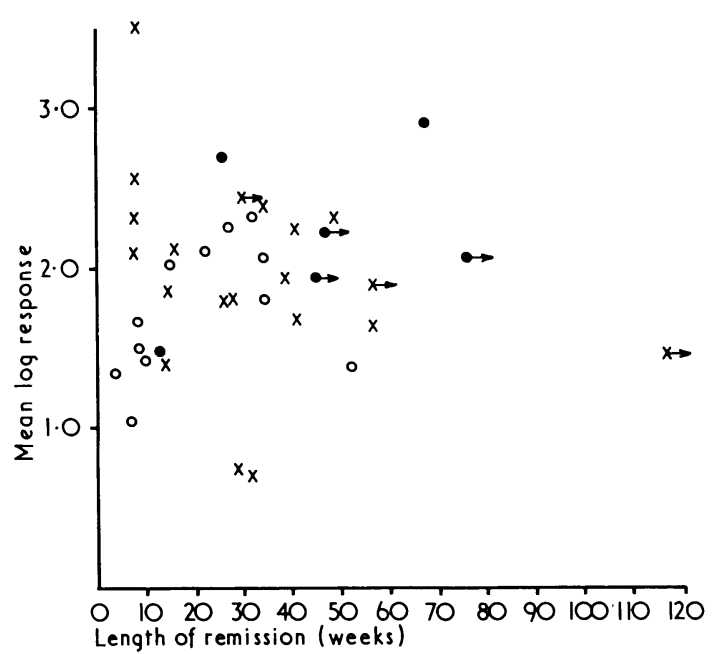

FIG. 1-Relation between mean phytohaemagglutinin (PHA) response-

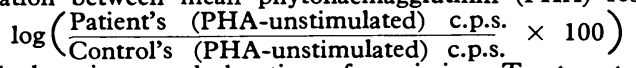

-of individual patients and duration of remission. Treatment groups : $X$, B.C.G.; O, no treatment; 0 methotrexate. Patients still in remission are indicated by arrows.

\section{Discussion}

The tumour-inhibitory effect of B.C.G. which has been clearly shown in animals-for example, Biozzi et al. (1959) and Old et al. (1959) - and suggested also in human leukaemia (Mathé, 1969), is thought to be due to its effect in stimulating cellular immunity. It is clear from these results that B.C.G. therapy has not increased lymphocyte responsiveness in this phytohaemagglutinin transformation test, nor has maintenance methotrexate treatment had any depressive effect. There is no obvious correlation between the phytohaemagglutinin response and the total length of remission, and no diminution in response shortly before relapse. In spite of the previous intensive treatment with cytotoxic drugs, there also seems to be no real difference between patients and controls; this has been noted in other cases of acute leukaemia by Astaldi et al. (1966) and Bardare et al. (1969). The controls were adults while the patients were mostly children, and it could be argued that in normal children the transformation might have been greater. 'Ths is unlikely, however, since we have found that the responsiveness of leukaemic children's lymphocytes to phytohaemagglutinin is no different from that of their healthy siblings (Jones, unpublished).

Transformation by phytohaemagglutinin has been shown by Tursi et al. (1969) to be a reasonably valid guide to cellular immunity in mice, and there is also the evidence that in severe immunity deficiency diseases the phytohaemagglutinin response is definitely decreased (Levene, 1970; Marshall et al., 1970). Oppenheim et al. (1970) and Fitzgerald (1971) pointed out, however, that the dose of phytohaemagglutinin which produces the maximum response, as used in the present investigation and in many other laboratories, may be 5 to 10 times as high as that which gives the most sensitive discrimination between normal and abnormal responses. It is possible that the use of a lower dose might show a difference or that another lymphocyte function test might do so-for example, response to streptokinase (Hersh, 1971) - but, alternatively, and perhaps most probably, there may be no discernible difference between the lymphocytes of normal children and of those in remission from acute lymphoblastic leukaemia, whichever of these forms of therapy is used.

This work was supported by grants from the Medical Research Council and the Leukaemia Research Fund. We are grateful to Dr. J. Stuart from the Children's Hospital, Birmingham, for kindly allowing patients under his care to be included in this study. We should also like to thank Sheila Ayliffe, Caroline Clayton, and Lena Gordon for their valuable technical help and Gail Raynsford for help with the statistical analysis.

\section{References}

Astaldi, G., Massimo, L., Airo, R., and Mori, P. G. (1966). Lancet, 2,

Bardare, M., Accorsi, A., Apollonio, T., and Careddu, P. (1969). Minerva Pediatrica, 21, 1019.

Biozzi, G., Stiffel, C., Halpern, B. N., and Mouton, D. (1959). Comptes Rendus des Séances de la Société de Biologie, 153, 987.

Coulson, A. S., and Chalmers, D. G. (1967). Immunology (London) 12, 417.

Fitzgerald, M. G. (1971). Clinical and Experimental Immunology, 8, 421. Hersh, E. M. (1971). Proceedings of the Tenth International Cancer Congress. In press.

Levene, G. M. (1970). Proceedings of the Royal Society of Medicine, 63, 349.

Lischner, H. W., Punnett, H. H., and DiGeorge, A. M. (1967). Nature, 214, 580 .

Marshall, W. C., Cope, W. A., Soothill, J. F., and Dudgeon, J. A. (1970). Proceedings of the Royal Society of Medicine, 63, 351

Mathé, G. (1969). British Medical fournal, 4, 7.

Medical Research Council Childhood Leukaemia Working Party (1971). British Medical fournal, 4, 189.

Old, L. J., Clarke, D. A., and Benacerraf, B. (1959). Nature, 184, 291. Oppenheim, J. J., Blaese, R. M., and Waldman, T. A. (1970). Fournal of Immunology, 104, 853.

Pentycross, C. R. (1968), fournal of Clinical Pathology, 21, 175.

Tursi, A., Greaves, M. F., Torrigiani, G., Playfair, J. H. L., and Roitt, I. M. (1969). Immunology, 17, 801 . 